\section{First Report of Vaccinium arboreum Hybrids with Cultivated Highbush Blueberry}

\author{
Paul M. Lyrene \\ Horticultural Sciences Department, University of Florida, P.O. Box 110690, \\ Gainesville, FL 32611
} Additional index words. Vaccinium corymbosum, sparkleberry, polyploidy, wide hybridiza-
tion, blueberry breeding

\begin{abstract}
Over several years, we obtained no hybrids after pollinating thousands of flowers of cultivated tetraploid highbush blueberry (Vaccinium corymbosum L. hybrids, section $C$ yanococcus) with pollen from diploid $V$. arboreum Marshall (section Batodendron, sparkleberry), a drought-tolerant blueberry relative native in the southeastern United States. In an effort to produce tetraploid $V$. arboreum that could be crossed with highbush blueberry, more than 30,000 seeds were soaked in aqueous colchicine $(0.1 \%$ to $0.2 \%)$ for $24 \mathrm{~h}$ or more. The seeds were germinated, and putative tetraploid plants (selected based on morphological characteristics) were grown long enough to obtain pollen for microscopic examination. Twelve selected seedlings that produced unusually large pollen tetrads were used as pollen parents in crosses with more than $\mathbf{4 0}$ different tetraploid highbush cultivars and advanced selections. Eighty-six crosses, in which a total of 17,968 flowers were pollinated, gave 1,569 plants that were verified as hybrids after one growing season in the field. Hybrids varied from very weak to quite vigorous, some equaling highbush cultivars in vigor. A few vigorous hybrids were male-sterile, but most had at least some pollen fertility. Of the most vigorous $F_{1}$ hybrids, 12 of the most fertile, based on the amount of pollen shed and on the microscopic appearance of the pollen, were backcrossed to highbush cultivars, and 3919 backcross seedlings were obtained. These varied widely in vigor but averaged higher in vigor than their $F_{1}$ interspecific hybrid parents.
\end{abstract}

Vaccinium arboreum (sparkleberry; section Batodendron) is a widespread and abundant diploid blueberry species native in the southeastern United States (Stockton, 1976; Vander Kloet, 1988). It flowers in April in north Florida and produces numerous small, shiny black berries that ripen from midSeptember through October. The berries are barely edible, having large seeds, grit-like sclerids, and little juice. Vaccinium arboreum interests blueberry breeders for several reasons. In particular, it has a wide, deep root system, which makes the plants drought-tolerant, and it can grow well on soils of higher $\mathrm{pH}$ than any species in section Cyanococcus. Cultivated highbush blueberries require acid soil and have shallow, fibrous roots that require continuous moisture in the top meter of soil.

Several intersectional crosses have produced hybrids in Vaccinium (Ballington, 1980, 2001; Darrow and Camp, 1945; Rousi, 1963) but our attempts to cross diploid $V$. arboreum with tetraploid highbush cultivars have failed. In each of 4 different years, we obtained no hybrids after pollinating several hundred to several thousand flowers of southern highbush cultivars with pollen from $V$. arboreum (Lyrene,

Received for publication 18 Nov. 2010. Accepted for publication 9 Feb. 2011

This work was supported in part by USDA CSREES grant 2009-51181-06201.

e-mail Lyrene@ufl.edu. unpublished data). These failures were probably attributable in part to the triploid block, which is strong in Vaccinium (Darrow et al., 1944), along with other genetic crossing barriers between sections Batodendron and Cyanococcus. In 1981 , we crossed $V$. arboreum as a pollen parent with several clones of $V$. darrowii Camp (section Cyanococcus), a diploid close relative of highbush blueberry (Lyrene, 1991). These crosses produced hundreds of seedlings, some quite vigorous. Most of the hybrid seedlings that were grown to maturity flowered heavily each year but produced little or no fruit or seed when open-pollinated in the field.

Chavez and Lyrene (2009) studied meiosis in 10 of the hybrids and confirmed that they were diploid. Despite considerable chromosome pairing, meiotic irregularities were common, including univalents and multivalents at Metaphase I and a high frequency of irregular chromosome distributions at Anaphase I.

The fertility of wide-hybrid diploid plants can sometimes be increased by doubling the chromosome number (Clausen et al., 1945). Increased fertility at the tetraploid level may be the result of a higher frequency of bivalent chromosome pairing (amphidiploid pairing) or greater genetic buffering resulting from genetic redundancy in polyploids.

This study had two goals: 1) to see if hybrids could be obtained by crossing tetraploid highbush blueberry cultivars with tetraploid $V$. arboreum produced using colchicine and 2) to see if the hybrids would be sterile or fertile.
Beginning in 2004, a composite of openpollinated berries was harvested in each of 3 years from 30 or more $V$. arboreum trees growing in a 100-ha forest in Clay County, in northeast Florida, near Jacksonville. Vaccinium arboreum seedlings sometimes form large colonies from root sprouts. The trees from which the berries were harvested were widely dispersed, variable in berry size and shape, and clearly included many genotypes. Seeds were extracted and dried. In November of each harvest year, $\approx 10,000$ dry seeds were imbibed in aqueous colchicine (either $0.1 \%$ or $0.2 \%$ ) for $\approx 110 \mathrm{~h}$ and then planted without rinsing on peat in a greenhouse under mist. The colchicine treatment appeared to have little detrimental effect on germination, and several thousand seedlings were grown each year. Starting when the first seedlings reached the two- to six-leaf stage, the germination pots were examined weekly, and seedlings that had unusually thick hypocotyls, asymmetrical leaf shape, or other morphological indications of possible polyploidy were transplanted to trays of peat. In each of the 3 years, 200 to 500 seedlings were selected and transplanted. As the seedlings grew, they were repeatedly reselected, and those that maintained morphological indications of polyploidy were potted and saved. When these plants flowered, pollen tetrad diameter was measured for each plant using a compound microscope at $250 \times$, and 12 putative tetraploid plants were selected based on pollen size for use in crosses with tetraploid highbush cultivars. Pollen tetrads of the selected plants were conspicuously larger than those of diploid $V$. arboreum, but pollen size varied considerably from one putative tetraploid to another (data not shown).

During the crossing seasons of 2007, 2008, and 2009 (February through April), 17,968 emasculated flowers on tetraploid southern highbush selections were pollinated in a beeproof greenhouse using pollen from the 12 putative tetraploid $V$. arboreum plants. Three diploid $V$. arboreum clones from seed not treated with colchicine were used to pollinate 500 additional flowers on highbush cultivars. The seeds obtained were extracted, dried, and planted the next November on peat under mist in a greenhouse. Seedlings were transplanted to trays of peat in January and February and then to a fumigated high-density field nursery in late April or early May. In November and December, the seedlings in the field were evaluated subjectively for vigor and were classified as hybrid or not hybrid. Leaf color, leaf and stem pubescence, and the color and patterning of the bark on older wood were the most useful traits for distinguishing hybrids from nonhybrids. Hybridity was confirmed in late winter by the size and shape of inflorescence buds. By the time the plants flowered (mostly in March and April), no questions about hybrid identity remained.

Flower bud formation on the hybrids in the field contrasted strongly with that of highbush blueberries. By late December, flower buds were conspicuous on all highbush seedlings 
that flowered the next spring. On hybrid seedlings, no flower buds were apparent before January, and from 1 Feb. through 1 Apr., many hybrid plants that appeared to have no flower buds would have flowers nearing anthesis 2 weeks later. Throughout Feb. and Mar. 2009, plants were examined weekly, and 61 hybrids that showed signs of flowering were dug, potted, and brought to the greenhouse for backcrossing to southern highbush cultivars.

The first few flowers that opened on each hybrid plant were harvested, and pollen was examined under a microscope at $250 \times$. Pollen was dusted onto a drop of water on a microscope slide by rotating a flower between the thumb and index finger. The amount of pollen shed per flower was estimated subjectively compared with the amount of pollen typically obtained from highbush flowers. A minimum of 25 pollen tetrads (100 microspores) was examined for each plant, and the percentage of the spores that appeared to be large, plump, and potentially viable was estimated. Additional $F_{1}$ hybrids, mostly from the second year's crosses, were dug, potted, and assessed for pollen fertility in late winter and spring of 2010. In all, $91 \mathrm{~F}_{1}$ hybrid seedlings were examined for pollen fertility. Twelve $F_{1}$ hybrids were chosen for use in backcrosses to tetraploid highbush cultivars. Selection was based on the number of flowers available, the amount of pollen shed, and the apparent viability of the pollen as judged by the appearance of the pollen under the microscope. Three of the $F_{1}$ hybrids that had the most flowers were used both as pollen and seed parents in backcrosses to highbush.
Crosses were made in a greenhouse from which pollinating insects were excluded. Flowers were emasculated before or shortly after anthesis. Pollen from the male parent, collected as previously described, was transferred immediately to stigmas of emasculated flowers of the seed parent.

\section{Results}

Pollination of tetraploid highbush flowers with pollen from $\mathrm{V}$. arboreum. Pollination of 500 highbush flowers with pollen from three diploid $V$. arboreum plants in 2008 produced no seed (Table 1). This was consistent with the results of previous years. The 17,968 highbush flowers pollinated using pollen from the putative tetraploid $V$. arboreum plants gave 1,569 plants that were verified in the field as hybrids (Fig. 1), an average of 87 hybrids per 1,000 pollinated flowers (Table 1). Approximately $60 \%$ of the hybrids had medium to high vigor. The other $40 \%$ were weak and will probably die before flowering.

Although the crosses were not designed to test differences in hybrid production using different $V$. arboreum and highbush clones as parents, $V$. arboreum clones appeared to differ in effectiveness as pollenizers. For example, in $2009, V$. arboreum clone $08-478$ produced no hybrids after pollination of 2692 flowers on seven different highbush cultivars, whereas $V$. arboreum clone 07-544 produced 173 hybrids after pollination of 2272 flowers on eight different highbush clones (Table 1). Because of the failure of $08-478$ to produce hybrids, its pollen was re-examined the next year and was found to be larger than that of the diploid control plants but the smallest of the putative tetraploids.

When several crosses were made using the same $V$. arboreum pollen parent, the identity of the highbush female parent seemed to strongly affect the number and vigor of the $F_{1}$ hybrids obtained (data not shown). The experimental design did not permit statistical testing of these differences.

Fertility of $F_{1}$ hybrids. The $91 \mathrm{~F}_{1}$ hybrids from 2007 and 2008 crosses from which pollen was examined microscopically in 2009 and 2010 ranged from completely male-sterile to having $98 \%$ of the microspores well developed and presumably viable. The median percent microspore viability for the 91 hybrids was $\approx 40 \%$. By comparison, typical microspore viability estimated in the same way for Florida highbush cultivars and for $V$. arboreum ranges from $95 \%$ to $99 \%$.

The 16 backcrosses in which highbush was the seed parent gave 3290 seedlings from 2658 pollinated flowers, an average of 1238 hybrids per 1000 pollinated flowers (Table 2 ). The nine reciprocal backcrosses, in which the $F_{1}$ hybrid was the seed parent and highbush the pollen parent, yielded 620 seedlings from 766 pollinated flowers, an average of 809 seedlings per 1000 pollinated flowers. The difference in rate of seedling production for the two types of backcrosses was significant at $1 \%$ according to the chi-square test.

\section{Discussion}

Vigorous hybrids can be obtained by pollinating tetraploid highbush cultivars with

Table 1. Results of crosses in 2007, 2008, and 2009 between tetraploid highbush cultivars and selected Vaccinium arboreum clones.

\begin{tabular}{|c|c|c|c|c|c|c|c|c|c|c|c|}
\hline \multirow{3}{*}{$\begin{array}{l}V \text {. arboretum } \\
\text { pollen source }\end{array}$} & \multirow{3}{*}{$\begin{array}{c}\text { Crosses } \\
(\text { no. })^{z}\end{array}$} & \multirow{3}{*}{$\begin{array}{c}\text { Total } \\
\text { flowers } \\
\text { pollinated }\end{array}$} & \multirow{3}{*}{$\begin{array}{c}\text { Percent } \\
\text { set } \\
(\mathrm{avg})\end{array}$} & \multirow{3}{*}{$\begin{array}{c}\text { Berries } \\
\text { sampled } \\
\text { (no.) }\end{array}$} & \multirow{2}{*}{\multicolumn{2}{|c|}{ Plump seeds/berry }} & \multicolumn{3}{|c|}{ Number of hybrids after 1 year in the field } & \multirow{3}{*}{$\begin{array}{c}\text { Hybrids } \\
\text { per flower } \\
\text { (no.) }\end{array}$} & \multirow{3}{*}{$\begin{array}{c}\text { Plants } \\
\text { not hybrid } \\
\text { (no.) }\end{array}$} \\
\hline & & & & & & & & Medium & & & \\
\hline & & & & & (mean) & $\mathrm{SD}$ & Vigorous & vigor & Weak & & \\
\hline \multicolumn{12}{|l|}{2007} \\
\hline $06-730$ & 8 & 426 & 50.0 & 140 & 4.3 & 3.5 & 51 & 34 & 31 & 0.27 & 3 \\
\hline $06-753$ & 8 & 1619 & 33.7 & 130 & 8.4 & 5.4 & 82 & 88 & 164 & 0.21 & 12 \\
\hline $06-754$ & 4 & 347 & 14.7 & 34 & 2.9 & 2.3 & 2 & 7 & 9 & 0.05 & 0 \\
\hline \multicolumn{12}{|l|}{2008} \\
\hline $06-730$ & 12 & 2805 & & & & & 167 & 159 & 266 & 0.21 & 61 \\
\hline $06-753$ & 2 & 461 & & & & & 14 & 13 & 10 & 0.08 & 0 \\
\hline $06-754$ & 5 & 1157 & & & & & 30 & 10 & 11 & 0.04 & 14 \\
\hline $06-748$ & 1 & 110 & & & & & 0 & 0 & 0 & 0.00 & 0 \\
\hline BAQ 3-11 & 3 & 981 & & & & & 12 & 12 & 9 & 0.03 & 10 \\
\hline BAQ 9 & 2 & 441 & & & & & 0 & 2 & 17 & 0.04 & 0 \\
\hline $06-734$ & 5 & 962 & & & & & 13 & 16 & 38 & 0.07 & 9 \\
\hline $06-765-2 x^{y}$ & 1 & 117 & & & & & 0 & 0 & 0 & 0.00 & 0 \\
\hline $06-772-2 x$ & 1 & 202 & & & & & 0 & 0 & 0 & 0.00 & 0 \\
\hline $06-776-2 x$ & 1 & 181 & & & & & 0 & 0 & 0 & 0.00 & 0 \\
\hline \multicolumn{12}{|l|}{2009} \\
\hline $06-730$ & 4 & 762 & 42.9 & 40 & 6.0 & 4.4 & 16 & 14 & 25 & 0.07 & 59 \\
\hline $06-748$ & 3 & 762 & 34.6 & 40 & 3.4 & 2.6 & 16 & 10 & 7 & 0.04 & 43 \\
\hline BAQ 3-11 & 4 & 616 & 10.9 & 62 & 0.8 & 1.0 & 0 & 0 & 0 & 0.00 & 0 \\
\hline BAQ 9 & 1 & 44 & $100.0^{x}$ & 20 & 0.0 & 0.0 & 0 & 0 & 0 & 0.00 & 0 \\
\hline $07-544$ & 8 & 2272 & 17.8 & 70 & 9.8 & 6.8 & 102 & 37 & 34 & 0.08 & 36 \\
\hline $07-505$ & 2 & 344 & 6.4 & 20 & 5.4 & 3.7 & 19 & 8 & 11 & 0.11 & 4 \\
\hline $07-131$ & 1 & 479 & 14.8 & 20 & 3.2 & 1.7 & 0 & 0 & 0 & 0.00 & 37 \\
\hline 07-149 & 3 & 688 & 17.2 & 38 & 1.0 & 1.5 & 1 & 1 & 1 & 0.00 & 46 \\
\hline $08-478$ & 7 & 2692 & 6.0 & 51 & 3.4 & 5.5 & 0 & 0 & 0 & 0.00 & 74 \\
\hline
\end{tabular}

${ }^{2}$ Each cross had a different tetraploid highbush clone as seed parent

${ }^{\mathrm{y}}$ Clones marked $-2 \mathrm{x}$ were known diploids.

${ }^{\mathrm{x}}$ The female parent produced many parthenocarpic berries. 
pollen from $V$. arboreum plants grown from colchicine-treated seed. Because similar crosses using diploid $V$. arboreum had repeatedly failed block is an important barrier to crossing these species. However, our most successful $V$. arboreum parent gave an average of only 0.27 hybrid seedlings per highbush flower pollinated. By comparison, highbush $\times$ highbush crosses in our greenhouse typically average 10 to 20 seedlings per pollinated flower. Most of the $12 \mathrm{~V}$. arboreum plants used as pollen sources appeared to have high pollen fertility. Of the 11 clones for which data were recorded, three had $\approx 50 \%$ well-developed microspores and the other eight had more than $90 \%$. The low rate of hybrid production does not

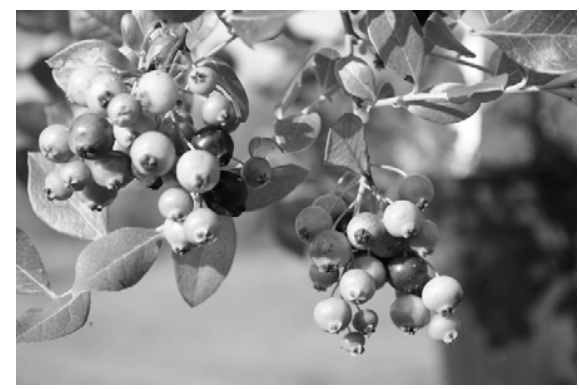

Fig. 1. Foliage and maturing fruit of an $\mathrm{F}_{1}$ hybrid (highbush cultivar $\times$ Vaccinium arboreum) after flowers were pollinated with pollen from a highbush cultivar. to produce hybrids, it appears that the triploid

appear to be the result of low fertility in the $V$. arboreum parents. Vaccinium arboreum and Vaccinium section Cyanococcus apparently have diverged enough genetically to make crosses difficult even when chromosome numbers are equal. Five of the tetraploid $V$. arboreum parent plants were planted together in a garden plot without other $V$. arboreum plants nearby. Four plants flowered heavily and produced berries in 2010 . One produced numerous berries, which had a median of nine well-developed seeds per berry, about the same as for diploid $V$. arboreum berries collected from the woods at the same time (Lyrene, unpublished data). The other three putative tetraploids produced numerous berries but had median seed-per-berry counts of only one, three, and four, respectively.

Both predictive models and experimental evidence indicate that, during the differentiation of two species from a common ancestor, crossing barriers arise when alleles evolve that work well within each species but interact destructively when the species are crossed (Matute et al., 2010; Moyle and Nakazato, 2010). As two species diverge over time, there is an increase in the number of loci bearing alleles that give unfavorable interactions when the two species are crossed. Many of the loci involved in cross-incompatibility are polymorphic for alleles that differ in their effects in hybrids (Kermicle and Evans, 2010). High heterozygosity in the parents we used and allelic polymorphism at many loci in each

Table 2. Results of backcrossing selected $\mathrm{F}_{1}$ (highbush $\times$ Vaccinium arboreum) hybrids to highbush in 2009.

\begin{tabular}{|c|c|c|c|c|c|}
\hline \multicolumn{6}{|c|}{ Highbush as female parent } \\
\hline \multicolumn{2}{|c|}{ Parents of cross } & \multirow[b]{2}{*}{$\begin{array}{c}\text { Flowers } \\
\text { pollinated (no.) }\end{array}$} & \multirow[b]{2}{*}{$\begin{array}{c}\text { Fruit } \\
\text { set }(\%)\end{array}$} & \multirow[b]{2}{*}{$\begin{array}{l}\text { Seedlings } \\
\text { (no.) }\end{array}$} & \multirow[b]{2}{*}{$\begin{array}{c}\text { Seedlings per } \\
\text { flower (no.) }\end{array}$} \\
\hline Highbush & $\begin{array}{c}\mathrm{F}_{1}(\text { highbush } \times \\
V . \text { arboreum })\end{array}$ & & & & \\
\hline Windsor & $08-445$ & 66 & 50.0 & 120 & 0.6 \\
\hline Sweetcrisp & $08-447$ & 293 & 46.8 & 250 & 0.9 \\
\hline Farthing & $08-447$ & 131 & 67.2 & 120 & 0.9 \\
\hline $05-613$ & $08-447$ & 91 & 42.9 & 100 & 1.1 \\
\hline Windsor & $08-444$ & 139 & 53.2 & 200 & 1.4 \\
\hline $00-116$ & $08-444$ & 43 & 65.1 & 150 & 3.5 \\
\hline $05-264$ & $08-444$ & 56 & 82.1 & 200 & 3.6 \\
\hline 03-291 & $08-454$ & 149 & 50.3 & 200 & 1.3 \\
\hline $06-600$ & $08-454$ & 251 & 43.4 & 300 & 1.2 \\
\hline Southern Belle & $08-467$ & 325 & 71.4 & 300 & 0.9 \\
\hline Abundance & $08-467$ & 274 & 42.3 & 400 & 1.5 \\
\hline Farthing & $08-467$ & 172 & 63.0 & 300 & 1.7 \\
\hline $08-14$ & $08-467$ & 213 & 52.1 & 300 & 1.4 \\
\hline Farthing & $08-461$ & 146 & 64.4 & 200 & 1.4 \\
\hline $05-323$ & $08-461$ & 187 & 22.5 & 100 & 0.5 \\
\hline Southern Belle & $08-479$ & 122 & 27.9 & 50 & 0.4 \\
\hline Total of all crosses & & 2658 & & 3290 & 1.2 \\
\hline \multicolumn{6}{|c|}{ F1 (highbush $\times$ Vaccinium arboreum) as female parent } \\
\hline $\begin{array}{l}\mathrm{F}_{1} \text { (highbush } \times \\
V . \text { arboreum })\end{array}$ & $\begin{array}{l}\text { Highbush } \\
\text { parent }\end{array}$ & $\begin{array}{c}\text { Flowers } \\
\text { pollinated (no.) }\end{array}$ & $\begin{array}{c}\text { Fruit } \\
\text { set }(\%)\end{array}$ & $\begin{array}{l}\text { Seedlings } \\
\text { (no.) }\end{array}$ & $\begin{array}{c}\text { Seedlings per } \\
\text { flower (no.) }\end{array}$ \\
\hline$\overline{08-479}$ & $01-233$ & 84 & 22.6 & 40 & 0.5 \\
\hline $08-464$ & $00-211$ & 33 & 6.1 & 15 & 0.5 \\
\hline $08-443$ & $98-325$ & 51 & 19.6 & 60 & 1.2 \\
\hline $08-442$ & $98-325$ & 104 & 6.7 & 40 & 0.4 \\
\hline $08-447$ & $01-233$ & 192 & 65.6 & 150 & 0.8 \\
\hline $08-488$ & Sweetcrisp & 64 & 35.9 & 100 & 1.6 \\
\hline $08-483$ & Sweetcrisp & 44 & 47.4 & 30 & 0.7 \\
\hline $08-467$ & Abundance & 76 & 34.2 & 150 & 2.0 \\
\hline $08-470$ & $01-233$ & 118 & 15.3 & 35 & 0.3 \\
\hline Total of all crosses & & 766 & & 620 & 0.8 \\
\hline
\end{tabular}

parent species probably explains why we were able to obtain some vigorous hybrids although most pollinated flowers gave nothing. The same considerations can explain the high variability observed in vigor and fertility of the $\mathrm{F}_{1}$ hybrids.

The $\mathrm{F}_{1}$ highbush $\times V$. arboreum hybrids varied greatly in male fertility. Some plants produced no pollen. Others shed pollen abundantly but with most of the pollen obviously aborted when viewed at $250 \times$. Still other plants produced abundant pollen with a high percentage of the microspores apparently well developed. Surprisingly, one $\mathrm{F}_{1}$ hybrid that seemed to be totally male-sterile based on microscopic examination of squashed anthers produced a full crop of highly seedy berries when placed outside the greenhouse with various highbush and $V$. arboreum plants. Thus, male sterility did not always indicate female sterility in these hybrids.

The $F_{1}$ hybrids selected for use in backcrosses (a sample biased toward higher fertility) were far more fertile in crosses to highbush than were any of the $V$. arboreum parents Large numbers of backcross (to highbush) seedlings can easily be obtained using the $F_{1}$ hybrids as either the male or female parent. The rates of production of backcross seedlings shown in Table 2 are minimum estimates for these crosses, because crossing conditions in the greenhouse were poor when the crosses were being made. The $F_{1}$ hybrid plants flowered very late, when the greenhouse was hot, and flower thrips (Frankliniella spp.) were visibly damaging many of the flowers. Very late flowering was characteristic of the $F_{1}$ hybrids, even when both the $V$. arboreum and the highbush parents had low chilling requirements. Very late flowering in $V$. arboreum was a major obstacle in producing the $\mathrm{F}_{1}$ hybrids, and late flowering seems to have come through strongly in the hybrids.

In many years of observing large populations of wild blueberry plants in the southeastern United States, I have never seen a plant that looked like a hybrid between $V$. arboreum and any other species. In north Florida, $V$. arboreum frequently occurs in association with $V$. darrowii and $V$. elliottii Chapman, both of which are diploid species in section Cyanococcus. The absence or infrequency of hybridization is undoubtedly attributable in part to the late flowering of $V$. arboreum but probably has additional genetic components.

With considerable effort, vigorous, fertile tetraploid hybrids and backcrosses can be made between cultivated highbush blueberry and tetraploid $V$. arboreum. Production of useful cultivars from this introgression will require much additional work. However, many potential benefits could come from $V$. arboreum introgression, including plants with increased drought tolerance, tolerance to higher soil $\mathrm{pH}$, late flowering, late ripening, upright canes, long peduncles and pedicels, and loose berry clusters. Segregating generations from these intersectional hybrids are expected to provide many opportunities for selecting novel plant types. 


\section{Literature Cited}

Ballington, J.R. 1980. Crossability between subgenus Cyanococcus (Gray) Klotzsch and subgenus Polycodium (Raf.) Sleumer in Vaccinium. HortScience 15:419.

Ballington, J.R. 2001. Collection, utilization, and preservation of genetic resources in Vaccinium. HortScience 36:213-220.

Chavez, D.J. and P.M. Lyrene. 2009. Hybridization of two diploid Vaccinium section Cyanococcus species with diploid Vaccinium arboreum in section Batodendron. Euphytica 171:263-272.

Clausen, J., D.D. Keck, and W.M. Hiesey. 1945. Experimental studies on the nature of species. II. Plant evolution through amphidiploidy and autoploidy with examples from the Madiinae.
Carnegie Inst. Washington Publ. no. 564, p. 62-73.

Darrow, G.M. and W.H. Camp. 1945. Vaccinium hybrids and the development of new horticultural material. Bull. Torrey Bot. Club 72:1-21.

Darrow, G.M., W.H. Camp, F.E. Fischer, and H. Dermen. 1944. Chromosomes in Vaccinium and related groups. Bull. Torrey Bot. Club 71: 498-506.

Kermicle, J.L. and M.S. Evans. 2010. The Zed mays sexual compatibility gene ga2: Naturally occurring alleles, their distribution, and role in reproductive isolation. J. Hered. 101:737749.

Lyrene, P.M. 1991. Fertile derivatives from sparkleberry $\times$ blueberry crosses. J. Amer. Soc. Hort. Sci. 116:899-902.
Matute, D.R., I.A. Butler, D.A. Turissini, and J.A. Coyne. 2010. A test of the snowball theory of hybrid incompatibilities. Science 329:15181521.

Moyle, L.C. and T. Nakazato. 2010. Hybrid incompatibility 'snowballs' between Solanum species. Science 329:1521-1523.

Rousi, A. 1963. Hybridization between Vaccinium uliginosum and cultivated blueberry. Annales Agriculturae Fenniae 2:12-18.

Stockton, L.A. 1976. Propagation and autecology of Vaccinium arboreum and its graft compatibility with Vaccinium ashei. MS thesis, Texas A\&M Univ.

Vander Kloet, S.P. 1988. The genus Vaccinium in North America. Agr. Canada Pub. 1828, Ottawa, Canada. 